\title{
Development and application of reverse genetic technology for the influenza virus
}

\author{
Ziquan $\mathrm{Li}^{1}{ }^{1} \cdot$ Liping Zhong $^{1} \cdot$ Jian $\mathrm{He}^{1} \cdot$ Yong Huang ${ }^{1} \cdot$ Yongxiang Zhao $^{1}$
}

Received: 14 August 2020 / Accepted: 28 December 2020 / Published online: 2 February 2021

(c) The Author(s) 2021

\begin{abstract}
Influenza virus is a common virus in people's daily lives, and it has certain infectivity in humans and animals. Influenza viruses have the characteristics of a high mutation rate and wide distribution. Reverse genetic technology is primarily used to modify viruses at the DNA level through targeted modification of the virus cDNA. Genetically modified influenza viruses have a unique advantage when researching the transmission and pathogenicity of influenza. With the continuous development of oncolytic viruses in recent years, studies have found that influenza viruses also have certain oncolytic activity. Influenza viruses can specifically recognize tumor cells; activate cytotoxic T cells, NK cells, dendritic cells, etc.; and stimulate the body to produce an immune response, thereby killing tumor cells. This article will review the development and application of influenza virus reverse genetic technology.
\end{abstract}

Keywords Influenza virus $\cdot$ Reverse genetic technology $\cdot$ Vaccine $\cdot$ Antitumor

\section{Introduction}

Genetics is traditionally defined as the phenotype and traits of an organism and represents a branch of science that studies the genetic composition of organisms, whereas reverse genetics is a process designed to identify the genetic composition of an organism and investigate the phenotype and traits at genetic level [1]. Reverse genetic technology is applied through targeted transformation of biological genes, such as by site-directed mutation, base insertion, deletion, replacement, etc., and then the transformed gene is modified and assembled so that it can be stably expressed $[2,3]$.

Influenza virus belongs to the genus Orthomyxovirus of the Orthomyxoviridae family which includes enveloped segmented single-stranded negative-sense RNA viruses [4]. Reverse genetic technology uses modified cloned cDNA to obtain infectious viruses to study the effect of these

Edited by Juergen A Richt.

Yongxiang Zhao

yongxiang_zhao@126.com

1 National Center for International Research of Bio-targeting Theranostics, Guangxi Key Laboratory of Bio-targeting Theranostics, Collaborative Innovation Center for Targeting Tumor Diagnosis and Therapy, Guangxi Medical University, Nanning 530021, Guangxi, China modifications on phenotypes. The reverse genetic system of influenza A virus was established by Luytjes and Enami in 1989 and 1990, respectively [5, 6]. In 1993, Takizawa discovered that influenza virus had a certain proapoptotic effect on MDCK and HeLa cells cultured in vitro and proposed for the first time that influenza virus could induce apoptosis in cultured cells in vitro [7]. In 1997, a positive signal of apoptosis was observed after a mouse was infected with influenza virus in the nasal cavity, and this signal showed that influenza virus can also cause apoptosis in the body [8]. Since then, the continuous development of reverse genetic technology has had a massive impact on the study of the transmission characteristics, infection mechanisms, and antitumor mechanisms of influenza viruses and the development of influenza vaccines. This article will review and discuss the reverse genetic technology of influenza virus and its research.

\section{Introduction to influenza virus}

Influenza viruses are spherical, and newly isolated viruses are generally $80-120 \mathrm{~nm}$ in size and consist of mostly filamentous particles up to $4000 \mathrm{~nm}$ [9]. The viral genome is approximately $13.6 \mathrm{~kb}$ and divided into 8 independent fragments of varying sizes. The 8 genome fragments encode 
the 8 structural proteins (PB1, PB2, PA, HA, NP, NA, M1, and M2) and nonstructural proteins (NS1 and NS2) of influenza virus [10] (Fig. 1). Because the nucleoprotein (NP) of influenza virus is highly conserved, it can be divided into three types: A, B, and C [11]. Influenza A virus is the main research object of this article. In addition to the above 10 essential proteins, the influenza A genome also encodes up to 7 nonessential accessory proteins (PB1-F2, N40, PA-X, PA-N155, PA-N182, M42, and NS3) [12-15]. Influenza A virus contains hemagglutinin (HA) and neuraminidase (NA). According to their antigenicity, the virus can be divided into $18 \mathrm{H}$ subtypes and $11 \mathrm{~N}$ subtypes.

\section{Main functional proteins of influenza virus}

The influenza virus genome encodes a variety of proteins, including proteins that play a decisive role in the replication, spread, infection, and pathogenicity of the virus. The polymerase of influenza A and B viruses is a complex of three proteins, namely, polymerase basic protein 1 (PB1), polymerase basic protein 2 (PB2) and polymerase acidic protein (PA). These proteins bind to one end of an antiparallel duplex formed by viral RNA and nucleoprotein (NP) and together form a viral ribonucleoprotein (vRNP) complex [16-19]. After virus infection, the vRNP is transported to the host cell nucleus and the modified viral RNA produces $c R N A$ and mRNA. The former

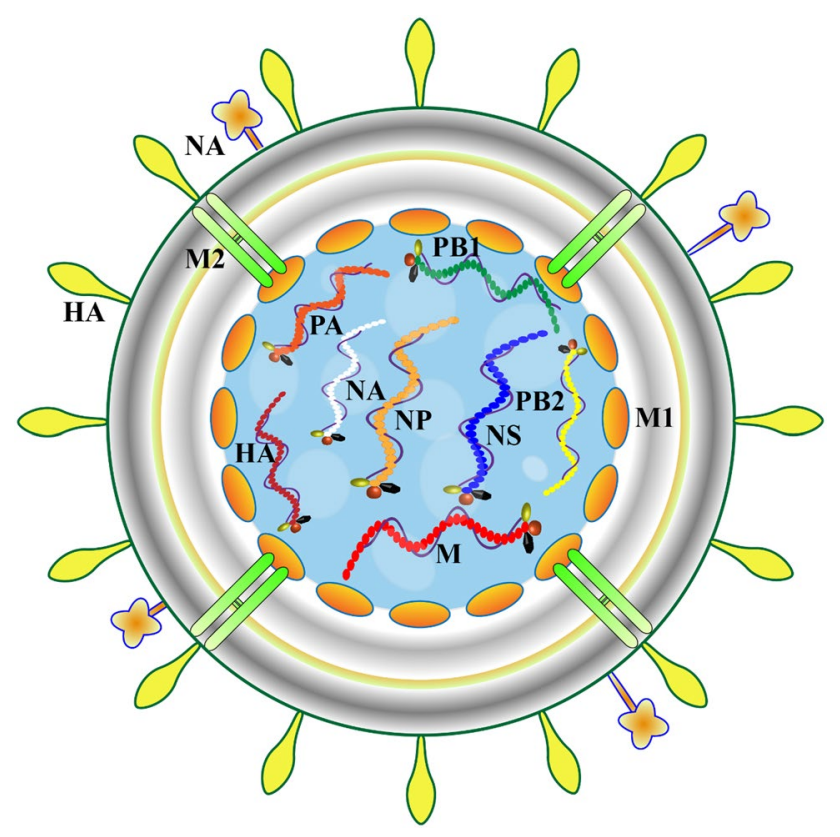

Fig. 1 Schematic diagram of the influenza virus structure. $H A$ hemagglutinin, $N A$ neuraminidase, $M 1$ matrix protein $1, M 2$ Matrix protein $2, P B 1$ polymerase basic protein $1, P B 2$ polymerase basic protein $2, N S$ nonstructural protein, $N P$ Nucleoprotein, $P A$ polymerase acidic protein is a template for progeny viral RNA replication, and the latter is a template for viral protein translation [20].

After infection by the virus, HA binds to the sialic acid receptor on the surface of the host cell and the virus invades the cell through receptor-mediated endocytosis. In addition, HA will also promote the fusion of the viral capsule and the host cell membrane [21-23]. HA will produce the polypeptide chain HA0 after translation, which is cleaved by host proteases into the HA1 and HA2 subunits, which become active HA proteins. HA1 is responsible for binding to the receptor, and HA2 is responsible for membrane fusion [24-26]. The main function of the NA protein of influenza virus is to cleave sialic acid on the surface of host cells or on the surface of newly generated virus particles. The NA protein can prevent the accumulation of virus particles on the cell surface and promote the release of new virus particles from the host cell after budding [27]. However, studies have shown that the sialidase activity of NA protein can also help viruses enter host cells [28]. In addition, the ratio of HA to NA on the virus particles can hinder viral passage through the receptor-rich mucus layer and ultimately affects the ability of the virus to infect host cells $[29,30]$.

The matrix protein 2 (M2) of influenza virus is a multifunctional modular protein. M2 constitutes the proton channel of the virus. The proton channel undergoes a conformational change in the acidic environment of intracellular vesicles, thus causing the protons in the intracellular vesicles to enter the virus particles through the proton channel. This activity promotes the fusion of the viral capsule with the intracellular vesicle membrane and the release of the vRNP complex into the cytoplasm [31, 32]. M2 can also stabilize the $\mathrm{pH}$ in the cytoplasm, prevent the conformational changes of HA, and promote the release of progeny viruses [33].

The matrix protein 1 (M1) of influenza virus is crucial for the assembly of virus particles, and M1 is also the main determinant of the shape of the virion [34]. Nonstructural protein 2 [NS2, also known as nuclear export protein (NEP)] mainly mediates the transport of vRNP from the nucleus to the cytoplasm. Recent studies have shown that the expression of NS2 is essential for determining the level of virus replication [35]. Nonstructural protein 1 (NS1) is an antagonist of the host's natural immune response induced by the virus [36]. The NS1 protein can inhibit the production of interferons in the host and the establishment of antiviral status. Similarly, NS1 also controls the synthesis and splicing of viral RNA, as well as restricts the host cell's mRNA polyadenylation [35].

\section{Life cycle of influenza virus}

Influenza virus replication refers to the whole process of virus particle invasion into the host cell to the final cellular release of the progeny virus, including adsorption, entry, 
uncoating, gene expression, assembly, and release (Fig. 2). Influenza viruses bind to sialic acid-terminating glycan receptors on the surface of host cells through HA. The vRNP complex is released into the cytoplasm through endocytosis. Low-pH conditions stimulate HA2-mediated membrane fusion and activate the M2 proton channel, thus accelerating the release of vRNP into the host cytoplasm [37]. The newly synthesized vRNP interacts with the M1 protein, is released outside the nucleus with the participation of the NS2 protein, and is incorporated into the progeny virus particles containing HA, NA and other proteins. The progeny viruses are then released outside the host cell through the cell membrane [38, 39].

\section{Overview of reverse genetics of viruses}

The reverse genetics of viruses is often called viral rescue, which is achieved by constructing an infectious clone of the virus and manipulating it in vitro at the DNA level to study the structure and function of the virus [40, 41]. Infectious molecular clones include infectious cDNA and infectious in vitro transcripts. To construct infectious cDNA, the cDNA fragment of the RNA virus genome is amplified by reverse transcription-polymerase chain reaction (RT-PCR), and restriction enzyme sites are used to clone it into a suitable vector to obtain a full-length cDNA clone of the genome. Using this clone to transfect appropriate cells, the full-length cDNA is replicated and transcribed, and it produces all the components of the virus in the cell and finally packages them into infectious virus particles [42, 43] (Fig. 3).

\section{Development of influenza virus reverse genetic technology}

Viruses can be divided into DNA viruses and RNA viruses according to their genome types. RNA viruses can be divided into positive-sense RNA viruses and negative-sense RNA viruses. When the whole genome RNA of a positivesense RNA virus is transfected into eukaryotic cells, its RNA can directly serve as mRNA [44, 45]. The genome of a negative-sense RNA virus cannot be used directly as a template for viral protein translation. To replicate normally, RNP complexes must be formed [46].

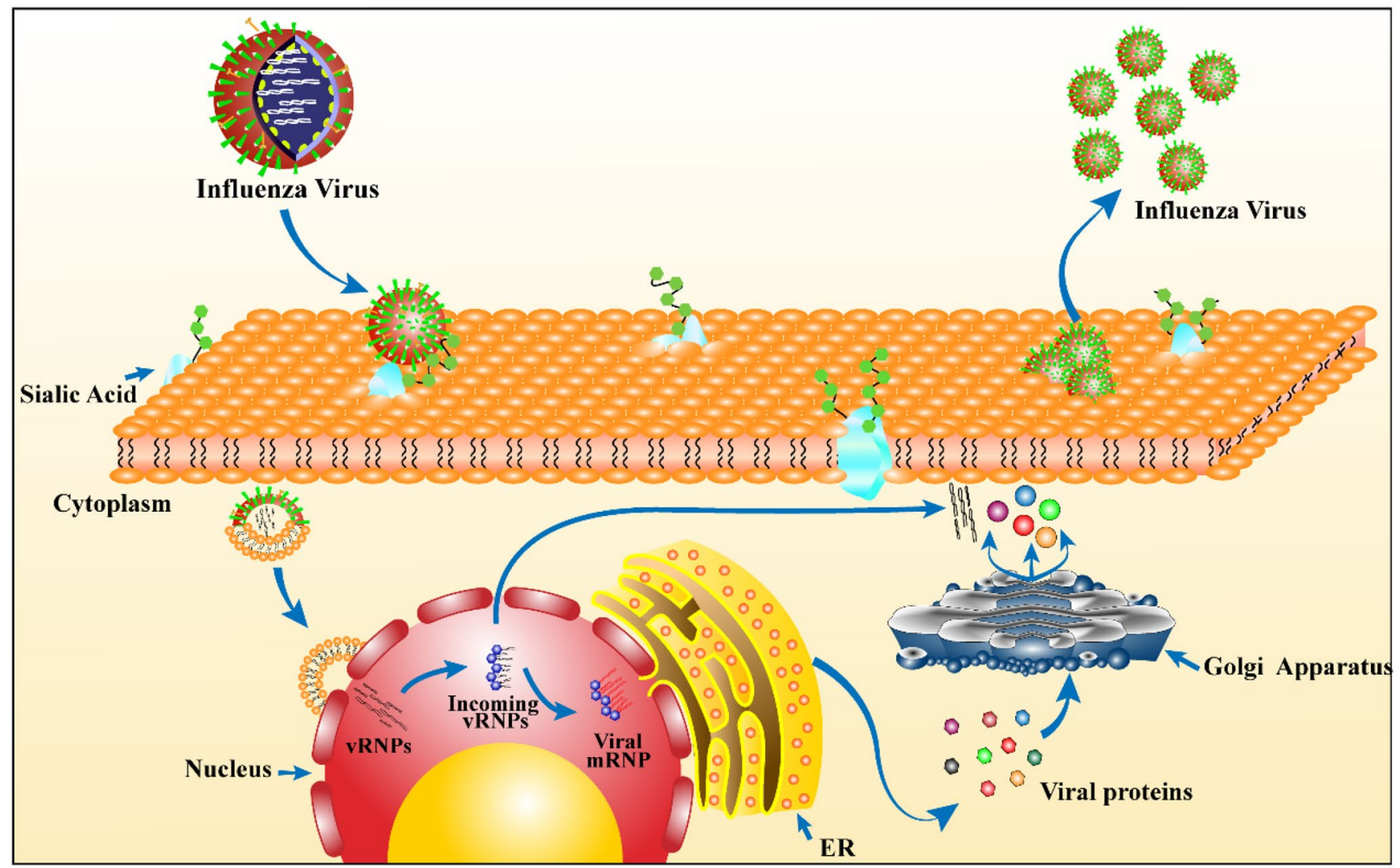

Fig. 2 Influenza virus infection of host cells. The HA of the influenza virus binds to the sialic acid-terminating glycan receptor on the surface of the host cell and enters the host cell through endocytosis. The
vRNP released by the virus enters the host cell nucleus and produces viral mRNA. By translating the newly generated viral protein and the progeny $\mathrm{vRNP}$, the progeny virus is synthesized again and released 


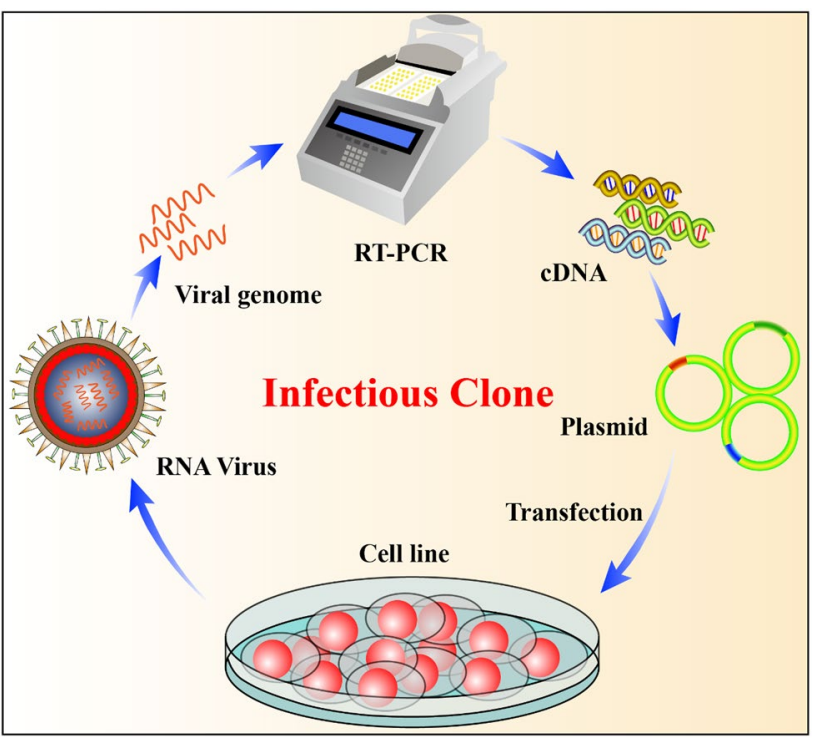

Fig. 3 Process of viral rescue. Viral RNA is extracted and reversetranscribed into RNA viral genomic cDNA by RT-PCR. The cDNA is inserted into the vector plasmid, and the recombinant virus is obtained by transfecting cells in vitro

In 1976, the first reverse genetic manipulation system for DNA viruses was established. Goff et al. successfully rescued in vitro DNA containing the artificial mutation SV40 [47]. In 1978, Taniguchi et al. established the first non-segmented reverse genetic manipulation system for positive-sense RNA viruses. The first in vitro rescue of an RNA virus, the $\mathrm{Q} \beta$ phage, was achieved, and the difficulty of RNA virus rescue was overcome [48]. It was not until 1989 that the Palese research team completed the manipulation of the genome of a negative-sense RNA virus for the first time, which became the starting point of reverse genetic research of negative-sense RNA viruses [5]. In 1994, Neumann et al. successfully achieved the use of the human RNA polymerase I system to transcribe RNA fragments of influenza virus in cells, which laid the foundation for the establishment of the reverse genetic system of influenza virus [49]. Subsequently, the scientists used the T7 RNA polymerase system to establish a reverse genetic system for a plasmid-based, non-segmented negative-sense rabies virus [50]. In the next few years, scientists used similar methods to establish a variety of reverse genetic systems of non-segmented negativesense RNA viruses, such as human respiratory syncytial virus, parainfluenza virus, Sendai virus, and rinderpest virus [51-54]. Building on the success of these practices, Bridgen and Elliott used the T7 RNA polymerase system to establish a reverse genetic system for Bunya virus. The Bunya virus genome is a negative-sense RNA virus divided into 3 segments [55].

In 1999, Neumann et al. of the Kawaoka research team established for the first time a completely plasmid-based reverse genetic system for influenza viruses. This system clones the cDNAs of eight kinds of RNA fragments of influenza virus into a plasmid vector containing the human RNA polymerase I promoter and mouse RNA polymerase I terminator one by one. The genes encoding nine viral proteins (PB2, PB1, PA, HA, NP, NA, M1, M2, and NS2) were cloned into the protein expression vector containing the RNA polymerase II promoter and poly-A signal one by one. For the first time, this study eliminated the large amount of screening processes required for auxiliary viruses, which was a large step toward the rescue of influenza viruses in vitro [56]. Since then, Fordor et al. also established a reverse genetic system for influenza virus in 1999. Unlike the 17-plasmid system of Neumann et al. they used a 12-plasmid system to rescue influenza virus [57]. The so-called 12-plasmid system includes PB2, PB1, PA and NP, four RNA polymerase II expression plasmids, and eight RNA polymerase I expression plasmids. The cells are transfected with these plasmids, which transcribe and express the viral genomic RNA and virus-related proteins in the cells, thereby producing infectious virus particles. Based on the 12-plasmid system, Hoffmann et al. further established an 8-plasmid system of influenza virus reverse genetic manipulation technology in 2000 [58] (Fig. 4). The system further improved the RNA polymerase I system and led to the invention of the "bidirectional vector", which indicates that the cDNA encoding the influenza virus gene fragment is positively inserted between the RNA polymerase II promoter and the poly-A signal, and then the RNA polymerase I promoter and terminator sequences are inserted in reverse at both ends. This arrangement enables viral RNA replication and protein expression on the same template. Among them, RNA polymerase I is responsible for transcribing negativestrand viral RNA and RNA polymerase II is responsible for synthesizing positive-strand mRNA, thus reducing the 12 required plasmids to 8 . Current technology is mainly based on the 8-plasmid system; however, obtaining viral RNA and expressing viral proteins on the same template reduces the "elasticity" of the system. As a result, when studying gene delivery or viral proteins, if one or more fragments are missing or if a certain fragment(s) has a lethal mutation, then the virus cannot be rescued.

\section{Latest progress of influenza virus reverse genetic technology}

Based on the 12-plasmid system and the 8-plasmid system, Neumann et al. cloned the RNA polymerase I transcription units of all 8 gene fragments into one plasmid. The RNA polymerase II transcription unit expressing the three polymerase proteins PB2, PB1, and PA of the virus was cloned into another plasmid. In addition, the RNA polymerase II transcription 
Fig. 4 Schematic diagram of the influenza virus 8-plasmid reverse genetic operation process. MDCK and $293 \mathrm{~T}$ cells are co-transfected with plasmids containing 8 influenza virus gene fragments. MDCK cells are infected to identify whether the recombinant influenza virus can be successfully rescued. A large amount of recombinant virus is amplified by infected chicken embryos

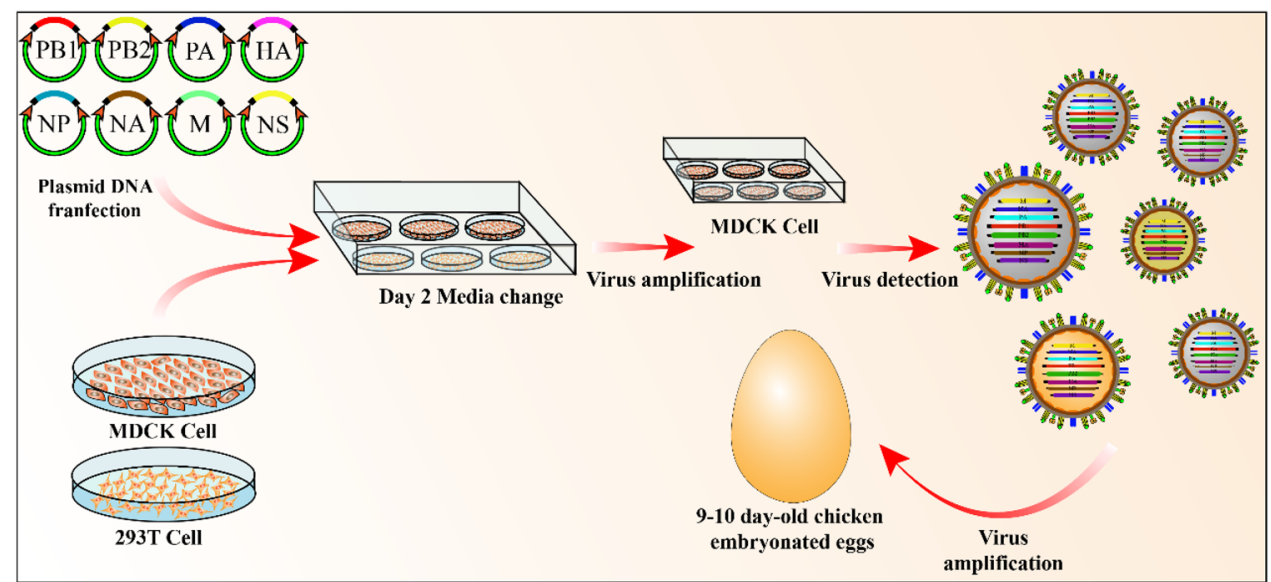

unit expressing the viral nuclear protein NP was cloned into a plasmid. With this system, only three plasmids need to be transfected to rescue influenza virus. This system can greatly improve the efficiency of influenza virus rescue in cell lines with low transfection efficiency (such as Vero cells) [59]. Subsequently, Zhang et al. cloned the bidirectional transcription unit of all 8 gene fragments of influenza virus into a plasmid. Transfecting this plasmid in chicken embryo fibroblasts can efficiently rescue influenza viruses [60]. In 2010, Muraki et al. established an influenza C virus-like particle (VLP) generation system and reverse genetic system [61]. Zhou similarly constructed the low-copy plasmid pGJ3C3 in 2011. This plasmid can be used to clone other unstable segments of influenza A virus and rescue recombinant virus. This technology has promoted basic research and vaccine production of influenza A virus [62]. Song et al. constructed a reverse genetic system using the Vero cell RNA polymerase I promoter to replace the traditional human RNA polymerase I promoter. The results showed that the Vero polymerase I promoter transcription level in Vero cells and the rescue efficiency of human RNA viruses were improved compared with those for the reverse genetic system transfection of 293 T cells containing the human polymerase I promoter [63]. Subsequently, Chen et al. cloned the bidirectional transcription unit of 8 gene fragments of influenza virus into bcmd-RGFlu. After transfection, these fragments can efficiently rescue influenza virus in a variety of cells [64]. Although these new attempts have greatly reduced the number of plasmids required to rescue influenza virus, the 8 gene fragments of the virus need to be integrated into one or several vectors at the same time, which significantly increases the difficulty and complexity of the cloning process (Fig. 5).

\section{Reverse genetic technology use in influenza virus pathogenicity research}

The application of reverse genetic technology has played an important role in the discovery of the factors that determine influenza virus pathogenicity. Studies have found that the low-pathogenicity avian influenza virus has only one alkaline arginine at the HA cleavage site and can be cleaved by trypsin-like proteases present in the respiratory and digestive tracts; therefore, the virus is generally restricted to replication in the respiratory and digestive tracts $[65,66]$. The highly pathogenic H5 and H7 subtype avian influenza viruses have multiple consecutive alkaline amino acids at the HA cleavage site that can be cleaved by proteases widely present in cells, which potentially leads to systemic infection [67]. A reverse genetic system was used to remove multiple basic amino acids from the HA cleavage site of highly pathogenic avian influenza virus, and the results showed that the virus's pathogenicity in poultry and mice was reduced [68]. During the epidemic of H5N1 avian influenza virus, 20 amino acids at positions 49 to 68 were deleted from the stem of the NA protein. Viruses containing this deletion expanded significantly in 2002. By 2007, all H5N1 avian influenza viruses had acquired this deletion [69]. After rescue of the mutant virus containing this deletion by reverse genetic technology, it was found that the NA stem deletion virus was significantly more pathogenic than the wild-type virus. At the same time, using reverse genetic technology, multiple amino acid mutations affecting the pathogenicity of influenza virus were found in the NS1 protein [70-72]. 


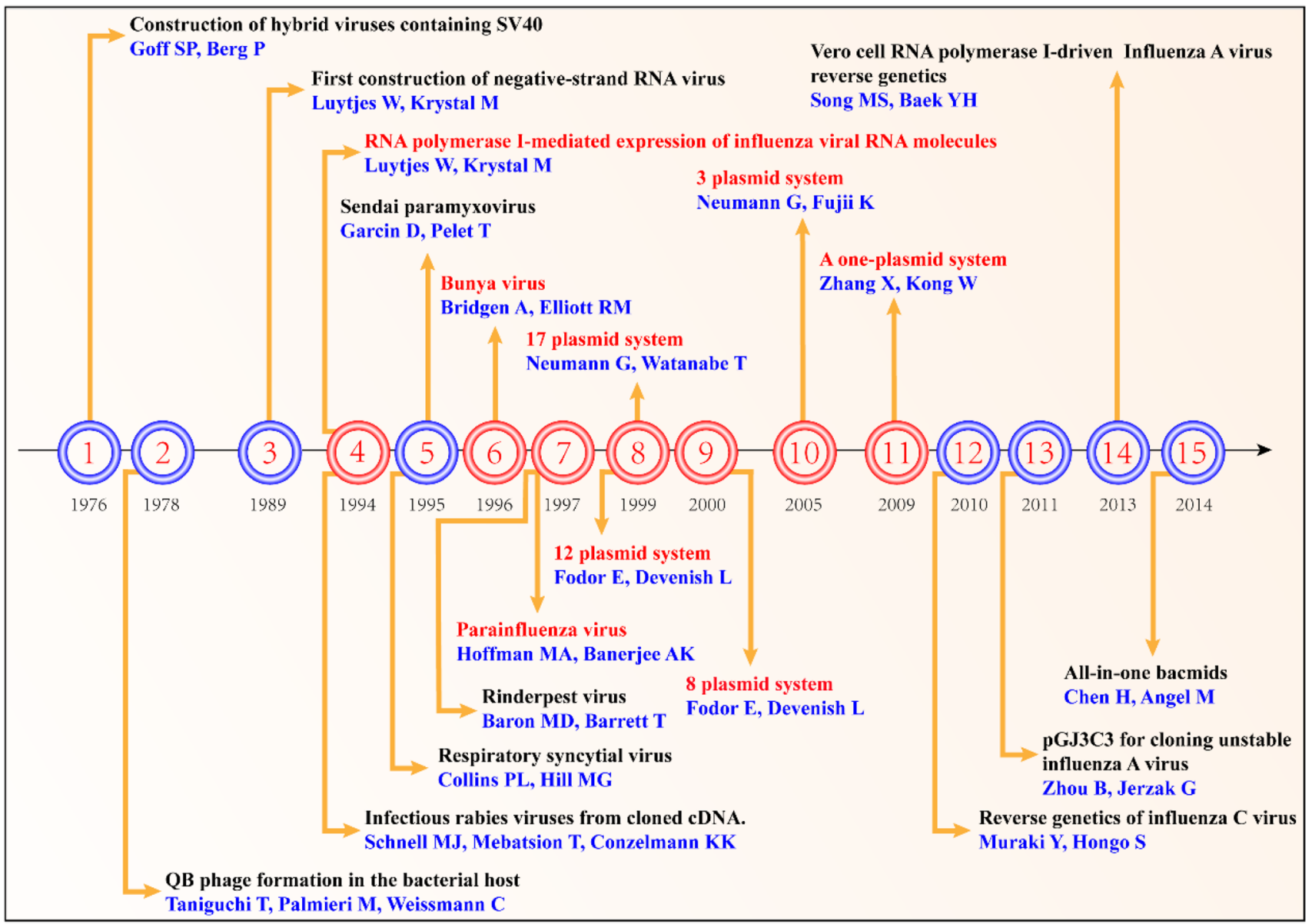

Fig. 5 Influenza virus reverse genetic technology development timeline. The timeline is from 1976 to 2014

\section{Influenza virus reverse genetics research for the development of new vaccines}

The best method of preventing flu is vaccination. Therefore, new and more effective influenza vaccines are urgently required. The three common forms in global influenza vaccine development are inactivated influenza vaccines, recombinant influenza vaccines and live attenuated influenza vaccines [73]. The recombinant influenza virus constructed by plasmid-based reverse genetic technology is an important object in the research of recombinant influenza vaccines. Single or multiple viral genome mutations contained in this form can provide additional research methods for new or improved vaccines.

With the development of influenza virus reverse genetic technology, inserting foreign epitopes into influenza virus protein structural domains to exert a better immune function has become an extensive research method. The most representative influenza virus vaccine vector is the coldadapted live attenuated influenza vaccine (LAIV), which has been approved for use in many countries [74-76]. The phenotype of the LAIV is controlled by multiple mutations in the internal protein genes of the donor virus. Therefore, the LAIV viral vector is relatively stable and the probability of reassortment with wild-type influenza virus is low $[77,78]$. In addition, recombinant vaccine vectors modified for influenza virus proteins are also widely used. Vaccine vectors targeting HA and NS1 are the most common. The stalk domain of the HA protein is relatively conserved among different subtypes of influenza viruses; therefore, the development of an influenza vaccine against the stalk domain of the HA protein is a new approach to influenza vaccine development. Studies have confirmed that viruslike particles composed of the HA protein with the missing head and the HA protein stem domain antigen are widely effective in clinical trials $[79,80]$. In addition, since NS1 can antagonize the host's innate immune type I interferon (IFN-I) response, a variety of potential vaccine strategies have been developed, and they are mainly based on the use of modified NS1 protein as a means of virus attenuation [81]. 


\section{Antitumor research using influenza virus reverse genetic technology}

\section{Antitumor application of influenza virus}

Although influenza virus is a pathogen that endangers human health, many studies have found that it has certain oncolytic ability as well. In 1993, Takizawa discovered that MDCK and HeLa cells cultured in vitro showed a series of specific changes in apoptosis after being infected with human influenza A virus, and he proposed for the first time that influenza virus can induce apoptosis in cultured cells in vitro [7]. In 1997, a positive signal of apoptosis was observed in the mouse nasal cavity after infection with influenza virus, indicating that influenza virus can also cause apoptosis in the body [8]. Afterward, an influenza virus vector with MAGE-3 constructed by Storbel et al. could transfect human dendritic cells (DCs) and highly express MAGE-3. The transfected DC phenotype does not affect its antigen presentation function and can stimulate the generation of MAGE-3-specific cytotoxic T lymphocytes (CTLs) [82]. These cells can induce an effective antitumor immune response. Sanda Sturlan et al. constructed replication-deficient influenza A virus, induced peripheral mononuclear cells to produce IFN- $\gamma$, activated CTLs, and induced CD8+ immune pathways to kill tumor cells [83]. $\mathrm{R}$ Weiss constructed an influenza virus vector expressing IL-24, which can enhance influenza virus-mediated apoptosis. Studies have found that the recombinant virus has stronger oncolytic activity than the virus alone and IL-24 [84]. Recently, Jennifer R. Hamilton et al. inserted antiCTLA4 antibodies into the PB1 and PA segments of influenza virus and found that it had good therapeutic effects in mice with aggressive B16-F10 melanoma [85].

\section{Apoptosis and influenza virus}

Typical features of apoptosis include DNA fragmentation, phosphatidylserine exposure on the cell membrane, plasma membrane deformation and blistering, and apoptotic body formation. Apoptosis can generally be divided into intracellular pathways and extracellular pathways. Influenza virus infection is a factor that causes apoptosis. It can cause apoptosis through intracellular pathways or extracellular pathways [86]. Studies have found that the PB1-F2 protein expressed by the influenza virus can interact with mitochondria in infected cells, change the permeability of the mitochondrial membrane, and accelerate the release of cytochrome $\mathrm{c}$ and the production of apoptotic bodies, thereby internally causing cellular apoptosis [87-89]. In addition, after influenza virus infects host cells, this protein also promotes the expression of Fas cell surface death receptor ligand (Fasl) and tumor necrosis factor-related apoptosis-inducing ligand (TRAIL) and other death receptor ligands, which externally cause cell apoptosis [90, 91].

\section{Immunity and influenza virus}

The elimination of the virus by the human immune system is an important barrier against influenza. Understanding the mechanism of the human body's response to influenza viruses can help transform influenza viruses into ideal oncolytic viruses. When the influenza virus infects the human body, it is first cleared by the mucus of the respiratory epithelium. After the influenza virus has passed through the mucus layer infects immune cells or non-immune cells, its viral RNA is recognized as a foreign substance and stimulates the body's secretion of IFN-I, proinflammatory cytokines, etc. Additionally, IFN produced by macrophages and DCs will promote the expression of hundreds of antiviral genes in the surrounding cells of the infected cell [92]. The virus protein will then be degraded into peptide fragments in antigen-presenting cells (APCs). These peptide fragments will be presented to T lymphocytes by MHC class I or class II molecules to stimulate the proliferation and differentiation of $\mathrm{T}$ lymphocytes into effector $\mathrm{T}$ cells and memory $\mathrm{T}$ cells. Effector T cells are responsible for eliminating infected cells and secreting antiviral cytokines. Memory $\mathrm{T}$ cells are responsible for reimmunization responses [93]. Infected cells will also become the target of NK cells. Finally, innate immunity, humoral immunity and cellular immunity are used to jointly construct the body's antiviral state.

\section{Antitumor mechanism of influenza virus}

After the influenza virus infects tumor cells, several methods of killing the tumor cells are observed. First, the virus can proliferate in the cell and lyse the tumor cells. The virus particles released after cell lysis can infect other cells again until all the tumor cells are killed [85, 94, 95]. Second, influenza viruses express proteins that are cytotoxic to tumor cells during the cell replication cycle, and they also stimulate the body to produce tumor cell-specific and non-specific immune responses [96]. Tumors can escape the body's immunity largely because tumor cells can reduce the expression of major histocompatibility antigens and their stimulating factors so that the body cannot produce an effective immune response. An influenza virus constructed by reverse genetic technology can express some proteins on the surface of tumor cells after infecting the tumor cells, thereby stimulating the body's immune system to recognize the tumor cells and generate an immune response against them [85, 97] (Fig. 6). 


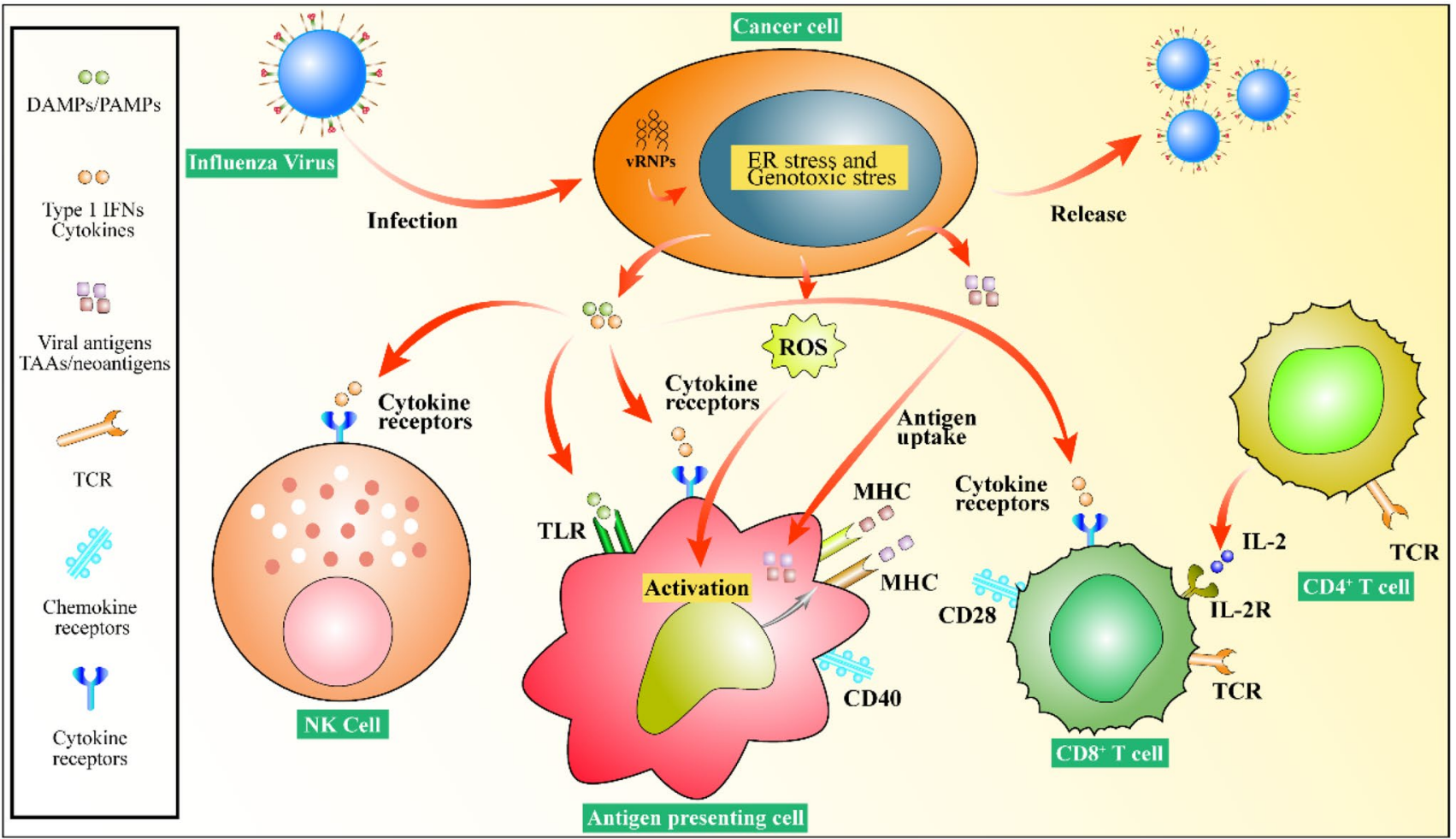

Fig. 6 Influenza viruses infect tumor cells and elicit an antitumor immune response. Influenza viruses can induce the release of DAMPs/PAMPs, type 1 IFNs, viral antigens, and TAAs/neoantigens

\section{Insufficient antitumor applications of influenza virus}

Modified influenza viruses still present certain problems when applied for tumor treatment. First, influenza viruses can only infect a portion of tumor cells. Therefore, designing a virus treatment plan that promotes the killing of adjacent uninfected cells will be a key point of influenza virus antitumor treatment. In addition, the safety of influenza viruses is also an important consideration. Although influenza virus is the most common human virus, from a safety perspective, the potential side effects caused by injecting live virus and returning non-disease-induced virus strains to a more pathogenic phenotype are controversial. In addition, due to the harsh tumor microenvironment, directly achieving tumor targeting is not always possible. These issues represent future challenges for influenza virus antitumor treatment.

\section{Future directions of influenza virus antitumor applications}

Antitumor research on influenza virus has made great progress in recent years with the development of reverse genetic technology. First, in terms of tumor immunotherapy, multiple recombinant influenza viruses expressing tumor after infecting tumor cells. These cytokines will activate NK cells, APCs. and T lymphocytes to strengthen the immune response against the tumor and achieve tumor treatment

necrosis factor and interleukin family members have been established, and they have good therapeutic effects on tumor models [95, 98-100].

In addition, treating tumors by targeting their own immune characteristics represents a new direction for recombinant influenza viruses. Tumor antigens need to be degraded into short peptides within APCs and then the antigen peptide MHC-TCR complex is formed and recognized by $\mathrm{T}$ cells to stimulate CTL responses. Therefore, when designing a cancer treatment plan, whether it will induce a cytotoxic immune response against cancer cells should be determined. Tumor-associated antigens (TAAs) are effective targets for immune response induction. The construction of an influenza virus vector expressing a TAA through reverse genetic technology can effectively induce a specific immune response to the TAA, thereby inducing the body's own immune system to target the tumor to achieve treatment $[96,101,102]$. DCs are currently the most powerful APCs in the body. In recent years, increasing evidence has shown that the cellular immunity activated by DCs, especially the $\mathrm{T}$ cell-mediated CTL response, plays a leading role in the body's antitumor activity [103-105]. Influenza virus vectors load foreign gene fragments to infect DCs and induce cellular immune responses. Using DCs to induce CTLs is an effective method for tumor immunotherapy. DCs that have 
been genetically modified to express TAAs can effectively induce antitumor immune responses and have potential cancer treatment capabilities [96].

In recent years, additional tumor immunotherapy methods have been applied, and activated macrophages represent an important treatment option. Additionally, with the deepening of research on influenza virus targeting of tumors, oncolytic activity may be increased. At present, with the continuous development of cancer drug research and development, the combined use of recombinant viruses and antitumor drugs has also become a new antitumor method [106].

\section{Conclusions}

In summary, reverse genetic manipulation technology has been used to redirect influenza viruses into viral vectors, which has good application prospects in clinical treatment and vaccine development. The oncolytic properties of influenza virus as well as its gene delivery vector ability can be applied to tumor therapy, including tumor vaccines and immunotherapy. Although the influenza virus poses a great threat to humans and has some problems in its application, continuous improvements in its transformation may promote the beneficial effects of this virus.

Author contributions All authors contributed to producing the manuscript.

\section{Compliance with ethical standards}

Conflict of interest All authors declare that they have no conflicts of interest.

Ethical approval This article does not contain any studies with human participants or animals performed by any of the authors.

Open Access This article is licensed under a Creative Commons Attribution 4.0 International License, which permits use, sharing, adaptation, distribution and reproduction in any medium or format, as long as you give appropriate credit to the original author(s) and the source, provide a link to the Creative Commons licence, and indicate if changes were made. The images or other third party material in this article are included in the article's Creative Commons licence, unless indicated otherwise in a credit line to the material. If material is not included in the article's Creative Commons licence and your intended use is not permitted by statutory regulation or exceeds the permitted use, you will need to obtain permission directly from the copyright holder. To view a copy of this licence, visit http://creativecommons.org/licenses/by/4.0/.

\section{References}

1. Chinnery PF, Cartlidge NE, Tennant S, Birchall D, Stenhouse SA (2004) Genetics in reverse. Lancet 363(9405):290. https:// doi.org/10.1016/s0140-6736(03)15387-1

2. Neumann G, Ozawa M, Kawaoka Y (2012) Reverse genetics of influenza viruses. Methods Mol Biol 865:193-206. https://doi. org/10.1007/978-1-61779-621-0_12

3. Kiraly J, Kostolansky F (2009) Reverse genetics and influenza virus research. Acta Virol 53(4):217-224. https://doi. org/10.4149/av_2009_04_217

4. Pu Z, Xiang D, Li X, Luo T, Shen X, Murphy RW, Liao M, Shen YY (2018) Potential pandemic of H7N9 Avian influenza A virus in human. Front Cell Infect Microbiol 8:414. https://doi. org/10.3389/fcimb.2018.00414

5. Luytjes W, Krystal M, Enami M, Parvin JD, Palese P (1989) Amplification, expression, and packaging of foreign gene by influenza virus. Cell 59(6):1107-1113. https://doi. org/10.1016/0092-8674(89)90766-6

6. Enami M, Luytjes W, Krystal M, Palese P (1990) Introduction of site-specific mutations into the genome of influenza virus. Proc Natl Acad Sci USA 87(10):3802-3805. https://doi. org/10.1073/pnas.87.10.3802

7. Takizawa T, Matsukawa S, Higuchi Y, Nakamura S, Nakanishi Y, Fukuda R (1993) Induction of programmed cell death (apoptosis) by influenza virus infection in tissue culture cells. J Gen Virol 74(Pt 11):2347-2355. https://doi. org/10.1099/0022-1317-74-11-2347

8. P'Iankova OG, Bulychev LE, Sergeev AN, Petrishchenko VA, P'Iankov OV, Zhukov VA, Zhukov VA, Ryzhikov AB, Kolesnikova NG, Evtin NK, Shishkina LN (1997) Some pathogenetic characteristics of influenza infection in white mice. Vopr Virusol 42(5):216-218

9. Dangi T, Jain A (2012) Influenza virus: a brief overview. Proc Natl Acad Sci India B 82(1):111-121. https://doi.org/10.1007/ s40011-011-0009-6

10. Ge S, Wang Z (2011) An overview of influenza A virus receptors. Crit Rev Microbiol 37(2):157-165. https://doi. org/10.3109/1040841X.2010.536523

11. Yang Z, Wang X, Tian L, Wang Y, Chen H (2008) Typing and subtyping avian influenza virus using DNA microarrays. Wei Sheng Wu Xue Bao 48(7):935-940

12. Spackman E (2020) A brief introduction to Avian influenza virus. Methods Mol Biol 2123:83-92. https://doi. org/10.1007/978-1-0716-0346-8_7

13. Vincent AL, Lager KM, Anderson TK (2014) A brief introduction to influenza A virus in swine. Methods Mol Biol 1161:243-258. https://doi.org/10.1007/978-1-4939-0758-8_20

14. Spackman E (2014) A brief introduction to avian influenza virus. Methods Mol Biol 1161:61-68. https://doi. org/10.1007/978-1-4939-0758-8_6

15. Dujarric De La Riviere R (1960) Conference on influenza A virus: introduction. Pathol Biol 8:2067-2069

16. Eisfeld AJ, Neumann G, Kawaoka Y (2015) At the centre: influenza A virus ribonucleoproteins. Nat Rev Microbiol 13:28-41. https://doi.org/10.1038/nrmicro3367

17. Miyake Y, Keusch JJ, Decamps L, Ho-Xuan H, Iketani S, Gut H, Kutay U, Helenius A, Yamauchi Y (2019) Influenza virus uses transportin 1 for vRNP debundling during cell entry. Nat Microbiol 4:578-586. https://doi.org/10.1038/s4156 4-018-0332-2

18. Morris AK, Wang Z, Ivey AL, Xie Y, Hill PS, Schey KL, Ren Y (2020) Cellular mRNA export factor UAP56 recognizes nucleic acid binding site of influenza virus NP protein. Biochem 
Biophys Res Commun 525(2):259-264. https://doi.org/10.1016/j. bbrc.2020.02.059

19. Hu Y, Liu X, Zhang A, Zhou H, Liu Z, Chen H, Jin M (2015) CHD3 facilitates vRNP nuclear export by interacting with NES1 of influenza A virus NS2. Cell Mol Life Sci 72(5):971-982. https ://doi.org/10.1007/s00018-014-1726-9

20. Yu Y, Qin HJ, Shi XX, Song JQ, Zhou JP, Yu P, Fan ZC, Zhong M, Yang Y (2020) Thiosialoside-decorated polymers use a twostep mechanism to inhibit both early and late stages of influenza virus infection. Eur J Med Chem 199:112357. https://doi. org/10.1016/j.ejmech.2020.112357

21. Vaidya NK, Huang H, Takagi S (2007) Modelling HA proteinmediated interaction between an influenza virus and a healthy cell: pre-fusion membrane deformation. Math Med Biol 24(3):251-270. https://doi.org/10.1093/imammb/dqm002

22. Dutch RE, Joshi SB, Lamb RA (1998) Membrane fusion promoted by increasing surface densities of the paramyxovirus $F$ and $\mathrm{HN}$ proteins: comparison of fusion reactions mediated by simian virus $5 \mathrm{~F}$, human parainfluenza virus type $3 \mathrm{~F}$, and influenza virus HA. J Virol 72(10):7745-7753. https://doi.org/10.1128/ JVI.72.10.7745-7753.1998

23. Mohebbi A, Fotouhi F, Jamali A, Yaghobi R, Farahmand B, Mohebbi R (2019) Molecular epidemiology of the hemagglutinin gene of prevalent influenza virus A/H1N1/pdm09 among patient in Iran. Virus Res 259:38-45. https://doi.org/10.1016/j. virusres.2018.10.001

24. Vazquez-Perez JA, De La Rosa-Zamboni D, Vega-Sanchez AE, Gutierrez-Gonzalez LH, Tellez-Navarrete NA, Campos F, Guadarrama-Pérez C, Sandoval JL, Castillejos-López M, JiménezJuárez RN, Sánchez-Huerta JL, Pérez-Méndez BB, Pérez-Padilla $\mathrm{R}$ (2019) Amino acid changes in HA and determinants of pathogenicity associated with influenza virus A H1N1pdm09 during the winter seasons 2015-2016 and 2016-2017 in Mexico. Virus Res 272:197731. https://doi.org/10.1016/j.virusres.2019.197731

25. Tung MC, Lu HY, Chang YK, Huang WR, Liao TL, Wu HY, Chang CD, Fan HC, Nielsen BL, Liu HJ (2020) Baculovirus surface display of the HA protein of H5N2 avian influenza virus and its immunogenicity against a lethal challenge with $\mathrm{H} 5 \mathrm{~N} 1$ virus in chickens. Vet Microbiol 243:108640. https://doi.org/10.1016/j. vetmic.2020.108640

26. Walters KA, Zhu R, Welge M, Scherler K, Park JK, Rahil Z, Wang H, Auvil L, Bushell C, Lee MY, Baxter D, Bristol T, Rosas LA, Cervantes-Medina A, Czajkowski L, Han A, Memoli MJ, Taubenberger JK, Kashet JC (2019) Differential effects of influenza virus NA, HA Head, and HA stalk antibodies on peripheral blood leukocyte gene expression during human infection. $\mathrm{mBio}$ 10(3):e00760-e819. https://doi.org/10.1128/mBio.00760-19

27. Li H, Hu P (2013) An analysis on HA, NA gene/protein evolution and the variability of antigenicity sites of influenza A (H7N9) virus. Zhonghua Yi Xue Za Zhi 93:2381-2384

28. Guo H, Rabouw H, Slomp A, Dai M, van der Vegt F, van Lent JWM, McBride R, Paulson JC, de Groot RJ, van Kuppeveld FJM, de Vries E, de Haan CAM (2018) Kinetic analysis of the influenza A virus HA/NA balance reveals contribution of NA to virus-receptor binding and NA-dependent rolling on receptorcontaining surfaces. PLoS Pathog 14(8):e1007233. https://doi. org/10.1371/journal.ppat.1007233

29. Du W, Guo H, Nijman VS, Doedt J, van der Vries E, van der Lee J, Li Z, Boons GJ, van Kuppeveld FJM, de Vries E, Matrosovich M, de Haan CAM (2019) The 2nd sialic acid-binding site of influenza A virus neuraminidase is an important determinant of the hemagglutinin-neuraminidase-receptor balance. PLoS Pathog 15(6):e1007860. https://doi.org/10.1371/journal.ppat.1007860

30. Vahey MD, Fletcher DA (2019) Influenza A virus surface proteins are organized to help penetrate host mucus. Elife 8:e43764. https://doi.org/10.7554/eLife.43764
31. Guo QY, Zhang LH, Zuo C, Huang DL, Wang ZA, Zheng JS, Tian CL (2019) Channel activity of mirror-image M2 proton channel of influenza A virus is blocked by achiral or chiral inhibitors. Protein Cell 10(3):211-216. https://doi.org/10.1007/s1323 8-018-0536-5

32. Dong H, Fiorin G, DeGrado WF, Klein ML (2014) Proton release from the histidine-tetrad in the $\mathrm{M} 2$ channel of the influenza A virus. J Phys Chem B 118(44):12644-12651. https://doi. org/10.1021/jp5102225

33. Torabifard H, Panahi A, Brooks CL 3rd (2020) M2 amphipathic helices facilitate $\mathrm{pH}$-dependent conformational transition in influenza A virus. Proc Natl Acad Sci USA 117(7):3583-3591. https://doi.org/10.1073/pnas.1913385117

34. Kordyukova LV, Shtykova EV, Baratova LA, Svergun DI, Batishchev OV (2019) Matrix proteins of enveloped viruses: a case study of influenza A virus M1 protein. J Biomol Struct Dyn 37(3):671-690. https://doi.org/10.1080/07391102.2018.1436089

35. Hao W, Wang L, Li S (2020) Roles of the non-structural proteins of influenza A virus. Pathogens 9(10):E812. https://doi. org/10.3390/pathogens9100812

36. Wacheck V, Egorov A, Groiss F, Pfeiffer A, Fuereder T, Hoeflmayer D, Kundi M, Popow-Kraupp T, Redlberger-Fritz M, Mueller CA, Cinatl J, Michaelis M, Geiler J, Bergmann M, Romanova J, Roethl E, Morokutti A, Wolschek M, Ferko B, Seipelt J, DickGudenus R, Muster T (2010) A novel type of influenza vaccine: safety and immunogenicity of replication-deficient influenza virus created by deletion of the interferon antagonist NS1. J Infect Dis 201(3):354-362. https://doi.org/10.1086/649428

37. Hu J, Zhang L, Liu X (2020) Role of post-translational modifications in influenza a virus life cycle and host innate immune response. Front Microbiol 11:517461. https://doi.org/10.3389/ fmicb.2020.517461

38. Lee HR, Lee MK, Kim CW, Kim M (2020) TRIM proteins and their roles in the influenza virus life cycle. Microorganisms 8(9):E1424. https://doi.org/10.3390/microorganisms8091424

39. Sharma S, Chatterjee A, Kumar P, Lal S, Kondabagil K (2020) Upregulation of miR-101 during Influenza A virus infection abrogates viral life cycle by targeting mTOR pathway. Viruses 12(4):444. https://doi.org/10.3390/v1204044441

40. Avila-Perez G, Nogales A, Park JG, Vasquez DM, Dean DA, Barravecchia M, Perez DR, Almazán F, Martínez-Sobrido L (2020) In vivo rescue of recombinant Zika virus from an infectious cDNA clone and its implications in vaccine development. Sci Rep 10(1):512. https://doi.org/10.1038/s41598-020-57545-2

41. Zhu YM, Hu ZL, Song QQ, Duan ZQ, Gu M, Hu SL, Wang XQ (2012) Construction and rescue of infectious cDNA clone of pigeon-origin newcastle disease virus strain JS/07/04/Pi. Bing Du Xue Bao 28(1):67-72

42. Anchisi S, Goncalves AR, Mazel-Sanchez B, Cordey S, Schmolke M (2018) Influenza A virus genetic tools: from clinical sample to molecular clone. Methods Mol Biol 1836:33-58. https://doi.org/10.1007/978-1-4939-8678-1_3

43. Lee CW (2014) Reverse genetics of influenza virus. Methods Mol Biol 1161:37-50. https://doi.org/10.1007/978-1-4939-0758-8_4

44. Zhang Z, He G, Filipowicz NA, Randall G, Belov GA, Kopek BG, Wang X (2019) Host lipids in positive-strand rna virus genome replication. Front Microbiol 10:286. https://doi. org/10.3389/fmicb.2019.00286

45. Bentley K, Evans DJ (2018) Mechanisms and consequences of positive-strand RNA virus recombination. J Gen Virol 99(10):1345-1356. https://doi.org/10.1099/jgv.0.001142

46. Pflug A, Lukarska M, Resa-Infante P, Reich S, Cusack S (2017) Structural insights into RNA synthesis by the influenza virus transcription-replication machine. Virus Res 234:103-117. https ://doi.org/10.1016/j.virusres.2017.01.013 
47. Goff SP, Berg P (1976) Construction of hybrid viruses containing SV40 and lambda phage DNA segments and their propagation in cultured monkey cells. Cell 9(4 PT 2):695-705. https://doi. org/10.1016/0092-8674(76)90133-1

48. Taniguchi T, Palmieri M, Weissmann C (1978) QB DNAcontaining hybrid plasmids giving rise to $\mathrm{QB}$ phage formation in the bacterial host. Nature 274(5668):223-228. https://doi. org/10.1038/274223a0

49. Neumann G, Zobel A, Hobom G (1994) RNA polymerase I-mediated expression of influenza viral RNA molecules. Virology 202(1):477-479. https://doi.org/10.1006/viro.1994.1365

50. Schnell MJ, Mebatsion T, Conzelmann KK (1994) Infectious rabies viruses from cloned cDNA. EMBO J 13(18):4195-4203

51. Baron MD, Barrett T (1997) Rescue of rinderpest virus from cloned cDNA. J Virol 71(2):1265-1271. https://doi.org/10.1128/ JVI.71.2.1265-1271.1997

52. Hoffman MA, Banerjee AK (1997) An infectious clone of human parainfluenza virus type 3. J Virol 71(6):4272-4277. https://doi. org/10.1128/JVI.71.6.4272-4277.1997

53. Garcin D, Pelet T, Calain P, Roux L, Curran J, Kolakofsky D (1995) A highly recombinogenic system for the recovery of infectious Sendai paramyxovirus from cDNA: generation of a novel copy-back nondefective interfering virus. EMBO J 14(24):6087-6094

54. Collins PL, Hill MG, Camargo E, Grosfeld H, Chanock RM, Murphy BR (1995) Production of infectious human respiratory syncytial virus from cloned cDNA confirms an essential role for the transcription elongation factor from the 5' proximal open reading frame of the M2 mRNA in gene expression and provides a capability for vaccine development. Proc Natl Acad Sci USA 92(25):11563-11567. https://doi.org/10.1073/pnas.92.25.11563

55. Bridgen A, Elliott RM (1996) Rescue of a segmented negativestrand RNA virus entirely from cloned complementary DNAs. Proc Natl Acad Sci USA 93(26):15400-15404. https://doi. org/10.1073/pnas.93.26.15400

56. Neumann $\mathrm{G}$, Watanabe $\mathrm{T}$, Ito $\mathrm{H}$, Watanabe $\mathrm{S}$, Goto $\mathrm{H}$, Gao P, Hughes M, Perez DR, Donis R, Hoffmann E, Hobom G, Kawaoka Y (1999) Generation of influenza A viruses entirely from cloned cDNAs. Proc Natl Acad Sci USA 96(16):9345-9350. https://doi.org/10.1073/pnas.96.16.9345

57. Fodor E, Devenish L, Engelhardt OG, Palese P, Brownlee GG, Garcia-Sastre A (1999) Rescue of influenza A virus from recombinant DNA. J Virol 73(11):9679-9682. https://doi.org/10.1128/ JVI.73.11.9679-9682.1999

58. Hoffmann E, Neumann G, Kawaoka Y, Hobom G, Webster RG (2000) A DNA transfection system for generation of influenza A virus from eight plasmids. Proc Natl Acad Sci USA 97(11):6108-6113. https://doi.org/10.1073/pnas.100133697

59. Neumann G, Fujii K, Kino Y, Kawaoka Y (2005) An improved reverse genetics system for influenza A virus generation and its implications for vaccine production. Proc Natl Acad Sci USA 102(46):16825-16829. https://doi.org/10.1073/pnas.0505587102

60. Zhang X, Kong W, Ashraf S, Curtiss R 3rd (2009) A one-plasmid system to generate influenza virus in cultured chicken cells for potential use in influenza vaccine. J Virol 83(18):9296-9303. https://doi.org/10.1128/JVI.00781-09

61. Muraki Y, Hongo S (2010) The molecular virology and reverse genetics of influenza C virus. Jpn J Infect Dis 63(3):157-165

62. Zhou B, Jerzak G, Scholes DT, Donnelly ME, Li Y, Wentworth DE (2011) Reverse genetics plasmid for cloning unstable influenza A virus gene segments. J Virol Methods 173(2):378-383. https://doi.org/10.1016/j.jviromet.2011.01.021

63. Song MS, Baek YH, Pascua PNQ, Kwon HI, Park SJ, Kim EH, Lim GJ, Choi YK (2013) Establishment of vero cell RNA polymerase I-driven reverse genetics for influenza A virus and its application for pandemic (H1N1) 2009 influenza virus vaccine production. J Gen Virol 94(Pt 6):1230-1235. https://doi. org/10.1099/vir.0.051284-0

64. Chen H, Angel M, Li W, Finch C, Gonzalez AS, Sutton T, Santos J, Perez DR (2014) All-in-one bacmids: an efficient reverse genetics strategy for influenza A virus vaccines. J Virol 88(17):10013-10025. https://doi.org/10.1128/JVI.01468-14

65. Muraina IA, Meseko CA, Fasina FO (2020) The potential of putative zinc-binding motifs of haemagglutinin (HA) protein for categorization and prediction of pathogenicity of $\mathrm{H} 5$ subtypes of avian influenza virus. Med Hypotheses 144:109925. https://doi. org/10.1016/j.mehy.2020.109925

66. Xu G, Wang F, Li Q, Bing G, Xie S, Sun S, Bian Z, Sun H, Feng Y, Peng X, Jiang H, Zhu L, Fan X, Qin Y, Ding J (2019) Mutations in PB2 and HA enhanced pathogenicity of H4N6 avian influenza virus in mice. J Gen Virol. https://doi.org/10.1099/ jgv.0.001192

67. Tian X, Landreth S, Lu Y, Pandey K, Zhou Y (2020) A replication-defective influenza virus harboring $\mathrm{H} 5$ and $\mathrm{H} 7$ hemagglutinins provides protection against $\mathrm{H} 5 \mathrm{~N} 1$ and $\mathrm{H} 7 \mathrm{~N} 9$ infection in mice. J Virol. https://doi.org/10.1128/JVI.02154-20

68. Chang P, Sealy JE, Sadeyen JR, Bhat S, Lukosaityte D, Sun Y, Iqbal M (2020) Immune escape adaptive mutations in the H7N9 Avian influenza hemagglutinin protein increase virus replication fitness and decrease pandemic potential. J Virol 94(19):e00216-e220. https://doi.org/10.1128/JVI.00216-20

69. Qi Y, Ni HB, Chen X, Li S (2020) Seroprevalence of highly pathogenic avian influenza (H5N1) virus infection among humans in mainland China: a systematic review and meta-analysis. Transbound Emerg Dis. https://doi.org/10.1111/tbed.13564

70. Pu J, Wang J, Zhang Y, Fu G, Bi Y, Sun Y, Liu J (2010) Synergism of co-mutation of two amino acid residues in NS1 protein increases the pathogenicity of influenza virus in mice. Virus Res 151(2):200-204. https://doi.org/10.1016/j.virusres.2010.05.007

71. Cui X, Ji Y, Wang Z, Du Y, Guo H, Wang L, Chen H, Zhu Q (2018) A 113-amino-acid truncation at the NS1 C-terminus is a determinant for viral replication of H5N6 avian influenza virus in vitro and in vivo. Vet Microbiol 225:6-16. https://doi. org/10.1016/j.vetmic.2018.09.004

72. Plant EP, Ilyushina NA, Sheikh F, Donnelly RP, Ye Z (2017) Influenza virus NS1 protein mutations at position 171 impact innate interferon responses by respiratory epithelial cells. Virus Res 240:81-86. https://doi.org/10.1016/j.virusres.2017.07.021

73. Hwang HS, Chang M, Kim YA (2020) Influenza-host interplay and strategies for universal vaccine development. Vaccines (Basel) 8(3):E548. https://doi.org/10.3390/vaccines8030548

74. Ang JC, Wang B, Wang JJF, Zeng PYF, Krammer F, Ward BJ, Russell ML, Loeb M, Milleret MS (2019) Comparative immunogenicity of the 2014-2015 northern hemisphere trivalent IIV and LAIV against influenza A viruses in children. Vaccines (Basel) 7(3):87. https://doi.org/10.3390/vaccines7030087

75. Rodriguez L, Blanco-Lobo P, Reilly EC, Maehigashi T, Nogales A, Smith A, Topham DJ, Dewhurst S, Kim B, Martínez-Sobridoet L (2019) Comparative study of the temperature sensitive, cold adapted and attenuated mutations present in the master donor viruses of the two commercial human live attenuated influenza vaccines. Viruses 11(10):928. https://doi.org/10.3390/ v11100928

76. Krutikova EV, Stepanova EA, Kiseleva IV, Rudenko LG (2019) Experimental study of genetic constellation of cold-adapted master donor viruses for live attenuated influenza vaccine type B. Bull Exp Biol Med 167:384-387. https://doi.org/10.1007/s1051 7-019-04532-x

77. Isakova-Sivak I, Tretiak T, Rudenko L (2016) Cold-adapted influenza viruses as a promising platform for viral-vector vaccines. Expert Rev Vaccines 15:1241-1243. https://doi. org/10.1080/14760584.2016.1208088 
78. Jang YH, Byun YH, Lee YJ, Lee YH, Lee KH, Seong BL (2012) Cold-adapted pandemic $2009 \mathrm{H} 1 \mathrm{~N} 1$ influenza virus live vaccine elicits cross-reactive immune responses against seasonal and H5 influenza A viruses. J Virol 86(10):5953-5958. https://doi. org/10.1128/JVI.07149-11

79. Wu NC, Wilson IA (2020) Structural biology of influenza hemagglutinin: an amaranthine adventure. Viruses 12(9):E1053. https://doi.org/10.3390/v12091053

80. Liao HY, Wang SC, Ko YA, Lin KI, Ma C, Cheng TR, Wong CH (2020) Chimeric hemagglutinin vaccine elicits broadly protective CD4 and CD8 T cell responses against multiple influenza strains and subtypes. Proc Natl Acad Sci USA 117(30):17757-17763. https://doi.org/10.1073/pnas.2004783117

81. Wang P, Zheng M, Lau SY, Chen P, Mok BW, Liu S, Liu H, Huang X, Cremin CJ, Song W, Chen Y, Wong YC, Huang H, Kai-Wong To K, Chen Z, Xia N, Yuen KY, Chen H (2019) Generation of DelNS1 influenza viruses: a strategy for optimizing live attenuated influenza vaccines. mBio 10(5):e02180-e2219. https://doi. org/10.1128/mBio.02180-19

82. Strobel I, Krumbholz M, Menke A, Hoffmann E, Dunbar PR, Bender A, Hobom G, Steinkasserer A, Schuler G, Grassmann R (2000) Efficient expression of the tumor-associated antigen MAGE-3 in human dendritic cells, using an avian influenza virus vector. Hum Gene Ther 11(16):2207-2218. https://doi. org/10.1089/104303400750035735

83. Sturlan S, Sachet M, Baumann S, Kuznetsova I, Spittler A, Bergmann M (2009) Influenza a virus induces an immediate cytotoxic activity in all major subsets of peripheral blood mononuclear cells. PLoS ONE 4(1):e4122. https://doi.org/10.1371/journal.pone.00041 22

84. Weiss R, Sachet M, Zinngrebe J, Aschacher T, Krainer M, Hegedus B, Walczak H, Bergmann M (2013) IL-24 sensitizes tumor cells to TLR3-mediated apoptosis. Cell Death Differ 20(6):823-833. https ://doi.org/10.1038/cdd.2013.15

85. Hamilton JR, Vijayakumar G, Palese P (2018) A recombinant antibody-expressing influenza virus delays tumor growth in a mouse model. Cell Rep 22(1):1-7. https://doi.org/10.1016/j.celre p.2017.12.025

86. Kabiljo J, Laengle J, Bergmann M (2020) From threat to cure: understanding of virus-induced cell death leads to highly immunogenic oncolytic influenza viruses. Cell Death Discov 6:48. https ://doi.org/10.1038/s41420-020-0284-1

87. Chen W, Calvo PA, Malide D, Gibbs J, Schubert U, Bacik I, Basta S, O’Neill R, Schickli J, Palese P, Henklein P, Bennink JR, Yewdell JW (2001) A novel influenza A virus mitochondrial protein that induces cell death. Nat Med 7(12):1306-1312. https://doi. org/10.1038/nm1201-1306

88. Wang R, Zhu Y, Ren C, Yang S, Tian S, Chen H, Jin M, Zhou H (2020) Influenza A virus protein PB1-F2 impairs innate immunity by inducing mitophagy. Autophagy. https://doi.org/10.1080/15548 627.2020.1725375

89. Leymarie O, Meyer L, Tafforeau L, Lotteau V, Costa BD, Delmas B, Chevalier C, Le Goffic R (2017) Influenza virus protein PB1-F2 interacts with CALCOCO2 (NDP52) to modulate innate immune response. J Gen Virol 98(6):1196-1208. https://doi.org/10.1099/ jgv.0.000782

90. Hornick EE, Dagvadorj J, Zacharias ZR, Miller AM, Langlois RA, Chen P, Legge KL, Bishop GA, Sutterwala FS, Cassel SL (2019) Dendritic cell NLRC4 regulates influenza A virus-specific CD4 T cell responses through FasL expression. J Clin Invest 129(7):28882897. https://doi.org/10.1172/JCI124937

91. Brincks EL, Gurung P, Langlois RA, Hemann EA, Legge KL, Griffith TS (2011) The magnitude of the T cell response to a clinically significant dose of influenza virus is regulated by TRAIL. J Immunol 187(9):4581-4588. https://doi.org/10.4049/jimmunol.1002241
92. Iwasaki A, Pillai PS (2014) Innate immunity to influenza virus infection. Nat Rev Immunol 14(5):315-328. https://doi. org/10.1038/nri3665

93. Jansen JM, Gerlach T, Elbahesh H, Rimmelzwaan GF, Saletti G (2019) Influenza virus-specific CD4+ and CD8+ T cell-mediated immunity induced by infection and vaccination. J Clin Virol 119:44-52. https://doi.org/10.1016/j.jcv.2019.08.009

94. Masemann D, Kother K, Kuhlencord M, Varga G, Roth J, Lichty BD, Rapp UR, Wixler V, Ludwig S (2018) Oncolytic influenza virus infection restores immunocompetence of lung tumor-associated alveolar macrophages. Oncoimmunology 7(5):e1423171. https ://doi.org/10.1080/2162402X.2017.1423171

95. Kuznetsova I, Arnold T, Aschacher T, Schwager C, Hegedus B, Garay T, Stukova M, Pisareva M, Pleschka S, Bergmann M, Egorov A (2017) Targeting an oncolytic influenza A virus to tumor tissue by elastase. Mol Ther Oncolytics 7:37-44. https://doi. org/10.1016/j.omto.2017.09.002

96. Efferson CL, Tsuda N, Kawano K, Nistal-Villán E, Sellappan S, Yu D, Murray JL, García-Sastre A, Ioannides CG (2006) Prostate tumor cells infected with a recombinant influenza virus expressing a truncated NS1 protein activate cytolytic CD8+ cells to recognize noninfected tumor cells. J Virol 80(1):383-394. https://doi. org/10.1128/JVI.80.1.383-394.2006

97. Iheagwara UK, Beatty PL, Van PT, Ross TM, Minden JS, Finn OJ (2014) Influenza virus infection elicits protective antibodies and T cells specific for host cell antigens also expressed as tumor-associated antigens: a new view of cancer immunosurveillance. Cancer Immunol Res 2(3):263-273. https://doi.org/10.1158/2326-6066. CIR-13-0125

98. Tanaka T, Kamiyama T, Daikoku T, Takahashi K, Nomura N, Kurokawa M, Shiraki K (2017) T-705 (Favipiravir) suppresses tumor necrosis factor alpha production in response to influenza virus infection: a beneficial feature of T-705 as an anti-influenza drug. Acta Virol 61(1):48-55. https://doi.org/10.4149/ av_2017_01_48

99. Hock K, Laengle J, Kuznetsova I, Egorov A, Hegedus B, Dome B, Wekerle T, Sachet M, Bergmann M (2017) Oncolytic influenza A virus expressing interleukin-15 decreases tumor growth in vivo. Surgery 161(3):735-746. https://doi.org/10.1016/j. surg.2016.08.045

100. Lara-Sampablo A, Flores-Alonso JC, De Jesus-Ortega N, SantosLopez G, Vallejo-Ruiz V, Rosas-Murrieta N, Reyes-Carmona S, Herrera-Camacho I, Reyes-Leyva J (2014) Transfection of influenza A virus nuclear export protein induces the expression of tumor necrosis factor alpha. Virus Res 185:1-9. https://doi.org/10.1016/j. virusres.2014.03.011

101. Patel JM, Vartabedian VF, Kim MC, He S, Kang SM, Selvaraj P (2015) Influenza virus-like particles engineered by protein transfer with tumor-associated antigens induces protective antitumor immunity. Biotechnol Bioeng 112(6):1102-1110. https://doi. org/10.1002/bit.25537

102. Dickhaut K, Hoepner S, Eckhard J, Wiesmueller KH, Schindler L, Jung G, Falk K, Roetzschke O (2009) Enhancement of tumourspecific immune responses in vivo by "MHC loading-enhancer" (MLE). PLoS ONE 4(9):e6811. https://doi.org/10.1371/journ al.pone.0006811

103. Bergamaschi C, Pandit H, Nagy BA, Stellas D, Jensen SM, Bear J, Cam M, Valentin A, Fox BA, Felber BK, Pavlakis GN (2020) Heterodimeric IL-15 delays tumor growth and promotes intratumoral CTL and dendritic cell accumulation by a cytokine network involving XCL1, IFN-gamma, CXCL9 and CXCL10. J Immunother Cancer 8(1):e000599. https://doi.org/10.1136/jitc-2020-000599

104. Yao Y, Chen L, Wei W, Deng X, Ma L, Hao S (2013) Tumor cellderived exosome-targeted dendritic cells stimulate stronger CD8+ CTL responses and antitumor immunities. Biochem Biophys Res Commun 436(1):60-65. https://doi.org/10.1016/j.bbrc.2013.05.058 
105. Wolfraim LA, Takahara M, Viley AM, Shivakumar R, Nieda M, Maekawa R, Liu LN, Peshwa MV (2013) Clinical scale electroloading of mature dendritic cells with melanoma whole tumor cell lysate is superior to conventional lysate co-incubation in triggering robust in vitro expansion of functional antigen-specific CTL. Int Immunopharmacol 15(3):488-497. https://doi.org/10.1016/j.intim p.2013.01.009

106. Sitnik S, Masemann D, Leite Dantas R, Wixler V, Ludwig S (2020) PD-1 IC inhibition synergistically improves influenza A virus-mediated oncolysis of metastatic pulmonary melanoma. Mol Ther Oncol 17:190-204. https://doi.org/10.1016/j. omto.2020.03.023

Publisher's Note Springer Nature remains neutral with regard to jurisdictional claims in published maps and institutional affiliations. 